International Journal of Pure and Applied Mathematics

Volume 84 No. 4 2013, 389-396

ISSN: 1311-8080 (printed version); ISSN: 1314-3395 (on-line version)

url: http://www.ijpam.eu

doi: http://dx.doi.org/10.12732/ijpam.v84i4.9

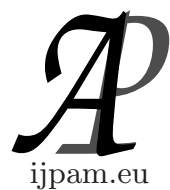

\title{
MODELING TARIFF TO ANALYZE PROTECTIONISM
}

\author{
Hossein Arsham \\ The Carey Business School \\ The Johns Hopkins University \\ 100 International Drive \\ Baltimore, MD 21202, USA
}

\begin{abstract}
The modeling of trading wars is now an actual and modern problem although the first works on optimization of the custom duties date back to the end of the 19th century. The problem of reducing the number of possible solutions to the conflict and precise identifying of the optimal strategies is important. Applying a mathematical model makes the problem more formal, allows removing political tension in search of optimum solutions to all participants of the trading conflict.

We consider that the some country sells a product manufactured both in the country and abroad to other countries. The country-consumer of the product faces a choice of the import regulation in relation to the situation by means of the import duty size. A goal of such regulation may be the income of taxes and customs payments or the growth of the domestic manufacturer part in sales volumes. A goal of the importer achieves by the import volume variation is either profit, or a number of workplaces in the countries making the imported product.
\end{abstract}

AMS Subject Classification: 91B60, 91B64, 91B44, 91B02, 91B66 Key Words: tariff policy, optimal tariffs, models of trade, trade policy

Received: December 30, 2012

(c) 2013 Academic Publications, Ltd. url: www.acadpubl.eu 


\section{Introduction}

The practice of an industry protection with an import tariff has long history and wide diversity. In this paper we consider very particular situation when given country decides to protect some branch of its economy understanding that this industry has all conditions to be brought up: there are all production factors needed, the output demand, open competitive space and so on. The Government may use the tariff approach to get fiscal benefits without any hopes to the industry development, to set the protection barrier which will change prices and help to the industry, but make suffer consumers, or to prohibit the import of any kind of goods under protection. This paper concerns the second case only. The difference between the levels of a tariff is considered in $[1,4,8]$.

More often the protection effect are analyzed from point of view the general equilibrium method [1-3, 6,12]. This allows estimating the tariff influence on different parts of society, involving in a model production functions. We emphasize onto partial problem relations among a government, producer and importer (smuggler) only. That approach is mentioned in $[9,10]$.

The attempt is undertaken to consider the dynamic model of protectionism taking into account the temporary coefficients in international trade [7, 11]. Inclusion in the analysis of such parameter as smuggling is caused by a simple observation, that if the barrier is fixed too high, the importers will find a pass through the border for smaller money [5].

General goal of the international trade is benefits of labor division: all countries would like to use their abundant factors outside and get being short factors and goods. Economic relations grow up for centuries, economic and political power of different countries is very different. It defines some special rules of international trade, which are covered by a number of trade agreements, regional and international. Some special institutes must watch on the trade practice. Besides it there are many particular agreements based on regional, political and other purposes. When one of such agreements starts a protection concerning the partners of the agreement there appears a political problem, which must be decided by politicians. It is not a problem of management. If the political decision is made there appears a task of a result optimization.

\section{Construction of Mathematical Model}

Considering the interrelations between the size of import of the given goods, the volume of domestic production, the difference between the customs duty 
and Value added Tax (VAT) for the domestic manufacturer, the volume of smuggling of the given goods and efficiency of the customs control. The mathematical model is constructed on the elementary assumptions that admit a clear economic interpretation.

Suppose that some goods (or service) on a home market are sold for the price $\mathrm{P}$, and all volume of sales consists of three parts: $x$ - homemade, $y$ - import and $z$-smuggling. The values are measured in terms of a unit of product; the price of unit of a product in the country, where the import is produced and the smuggling exists is measured in conditional units (for example, dollar). We will designate the customs duty as $\tau$, and the VAT as $s$.

According to the introduced designations, the following amount of money flows to the budget of the country from the customs and the tax committees

$$
S=\tau q y+s x p+\alpha z p
$$

where the latter summand reflects the realization of $\alpha z$ units of smuggling at the price pinside the country $(0 \leq \alpha \leq 1$ - coefficient of effectiveness of the customs house). The factor $\mathrm{q}$ is the price of the product abroad, and $\mathrm{y}$ is volume of import.

2.1 The basic assumptions: Let's consider that the population pays the constant sum $M$ for the given product, and the imported product is not substituted. Thus, the curve of demand has the form:

$$
p(x+y+z)=M .
$$

Let's consider also that the import is determined by the benefit of the importer who is capable to change the value depending on conditions of the home market. The profit of the importer will be calculated by the formula:

$$
D=y(p-q-\tau q) .
$$

The country-consumer of the product faces a choice of the import regulation in relation to the situation by means of the import duty size (or some quota system which is not spoken about in the given work). A goal of such regulation often is the income of taxes and customs payments and/or the growth of the domestic manufacturer part in sales volumes. A goal of the importer that it achieves by the import volume variation is either profit, or number of workplaces in the countries making the imported product that is proportional to the import volume.

The profit is a driving force of smugglers, therefore;

$$
G=z[(1-\alpha) p-q] .
$$


The motives of changes of volume of the domestic manufacturer can be various: the creation of jobs, the formation of the export potential of the country, strengthening of manufacture connected with national security, etc. In each case the law of change of the value $x$ depending on conditions of the market will act.

In the following we will consider three possible cases.

2.2 Case I: Let us assume that $x=$ const, $z=0$; i.e., there is no smuggling, and domestically manufacture has a constant value. Then, at fixed $\tau \geq 0$ the following relations will exist:

$$
\begin{gathered}
p_{\tau}\left(x+y_{\tau}\right)=M, \quad D_{\tau}=y_{\tau}\left[\frac{M}{x+y_{\tau}}-q(1+\tau)\right], \\
S_{\tau}=\tau q y_{\tau}+s x p_{\tau} .
\end{gathered}
$$

Let's assume that the importer implements the best strategy for him; i.e., $y_{\tau}=$ $\arg \max _{y_{\tau}} D_{\tau}\left(y_{\tau}\right)$. We will obtain the optimum strategy from a condition: $\frac{d}{d_{y_{\tau}}} D_{\tau}=0$.

This equation has the solution: $y_{\tau}=\sqrt{\frac{M x}{q(1+\tau)}}-x$.

It is obvious, that $y_{\tau}>0$, while $\tau<\frac{M}{q x}-1$. The price on the home market under this condition is calculated by the formula: $p_{\tau}=\sqrt{\frac{M q(1+\tau)}{x}}$.

Substituting the optimum $y_{\tau}, p_{\tau}$ in the formula for calculating the budget profits:

$$
S_{\tau}=s x \sqrt{\frac{M q(1+\tau)}{x}}+\tau q\left(\sqrt{\frac{M x}{q(1+\tau)}}-x\right) .
$$

Suppose that the state establishes a level $\tau$ of the customs duty based on the condition of the maximal deductions to the budget from the tax and the customs service; i.., from achievement of the highest value of the function $S_{\tau}$. One may simplify this function by replacing $\mu=\sqrt{1+\tau}$ :

$$
S_{\mu}=q\left(\mu^{2}-1\right)\left(\sqrt{\frac{x M}{q}} \frac{1}{\mu}-x\right)+\sqrt{x M q} \mu
$$

The dynamics of budget profits has a typical shape presented in Figure 1.

Figure 1: A typical dependence of budget profits on the customs tariff

Now taking into account the restrictions on $\tau$ to obtain the highest value of $S_{\mu}$ at $1<\mu<\sqrt{\frac{M}{x q}}$. Let $m=\sqrt{\frac{M}{x q}}$ then the highest value $S_{\mu}$ is determined 


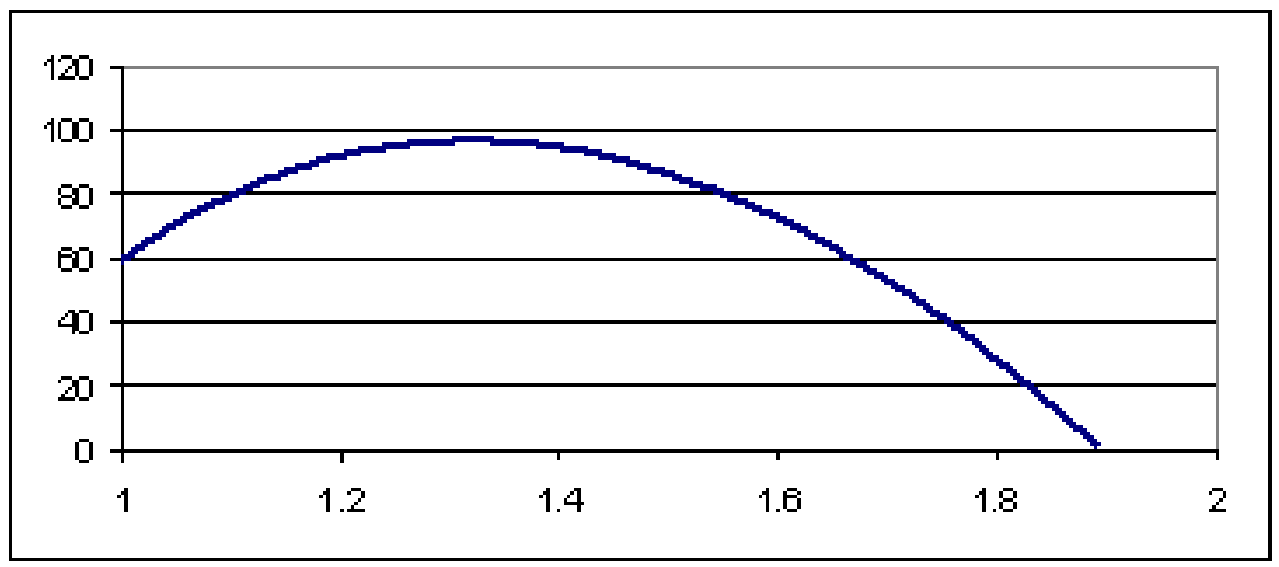

by the root of the equation:

$$
\mu^{3}-\frac{m(1+s)}{2} \mu^{2}-\frac{m}{2}=0
$$

In the given limits the root exists and it is the only root of the equation. It is possible to be shown graphically. The root can be calculated by the well-known formula of Cortano root finding:

2.3 Case II: Suppose that the industry of the country responds to growth of the price by expansion of production. And the expansion of manufacture; i.e. increase of $x$, can be carried out only at the expense of the funds received from the sale of an additionally manufactured product at the prices, which increased because of the customs duty. The equation of change will have the form:

$$
\dot{x}(t)=c x(t) x(t)\left[p_{\tau}(t)-p^{0}\right],
$$

where $p_{\tau}$ - the price which was established after introduction of the duty, $p^{0}-$ the price before introduction of the duty (it reflects the cost price because if $x$ units of product were on sale at that price, so $p^{0}$ would be higher than the cost price by the value of trade, transport, tax and other costs). The expansion of manufacture (increase of $x$ ) will be possible, if $p_{\tau}>p^{0}$ according to the equation (6). Here $c$ means a share of the income going to expansion of manufacture. From (6) it is seen, that its growth will be stopped, when $p_{\tau}=p^{0}$; i.e., with increase of $x$ the price determined by the function of demand (2), will fall down to $p^{0}$, if the importer does not change his behavior.

Let's assume that the importer continues to import $y_{\tau}$ units of a product, and the manufacturer, having received the credit, managed to increase the 
manufacture up to $\hat{x}$, so that:

$$
p^{0}\left(y_{\tau}+\hat{x}\right)=M
$$

Clearly one might take into account the time of repayment of credit and interest, or it is necessary to assume, that the necessary sum is received as the state grant.

Determining the profit of the state derives from: $S=\tau q y_{\tau}+s p^{0}\left(\frac{M}{p^{0}}-y_{\tau}\right)$. Let's show that the profit of the state is higher, if $y_{\tau}<y$; i.e., $\hat{x}>x$, so:

$$
\begin{aligned}
\Delta S & =\left(\tau q y_{\tau}=s x p_{\tau}\right)-\left(\tau q y_{\tau}+s p^{0}\left(\frac{M}{p^{0}}-y_{\tau}\right)\right)=s\left(\frac{x M}{x+y_{\tau}}-M+p^{0} y_{\tau}\right)= \\
& =\frac{s y_{\tau} p^{0}}{x+y_{\tau}}\left(y_{\tau}-y\right)<0 .
\end{aligned}
$$

The increment of the profit, which is optimal by $\tau, s$ can be obtained by the similar way. However, it is more expedient to consider the optimization of the profit of the state simultaneously with the influence on the coefficient $\mathrm{c}$ (i.e., expansion of manufacture), since the profit reduces the investments in manufacture. For example, the equation (6) can have the form:

$$
\dot{x}(t)=c(s) x(t)\left[p_{\tau}(t)-p^{0}\right],
$$

where $c(s)$ is a decreasing function $s$.

2.4 Case III: Finally, suppose there is a non-zero smuggling. This is possible, when there exists a customs barrier. Otherwise there is no sense to risk. For the sake of simplification we will assume, that $x=$ const. If $\alpha$ is a parameter of efficiency of the customs house, the customs will confiscated $\alpha z$ units of $z$ ones of the given product intended for smuggling, and $(1-\alpha) z$ find their way to the home market:

$$
p^{0}\left(y^{0}+x^{0}\right)=M, \quad p_{\tau}\left(y_{\tau}+z_{\tau}+x^{0}\right)=M,
$$

where $y_{\tau}-$ the optimal strategy of the importer. Then the profit of the importer is equal to:

$$
D=y_{\tau}\left[\frac{M}{y_{\tau}+z_{\tau}+x^{0}}-q(1+\tau)\right],
$$

and that of a smuggler:

$$
G=z_{\tau}\left[(1-\alpha) \frac{M}{y_{\tau}+z_{\tau}+x^{0}}-q\right] .
$$

Three general conclusions follow: 
1) if $(1-\alpha) p_{\tau}<q$, then $z_{\tau}=0$; i.e., the smuggling is absolutely unprofitable irrespective of existence of import;

2) If $\alpha p_{\tau}>q \tau$, then $z_{\tau}=0$; i.e. the smuggling is unprofitable in comparison to legal import;

3) If $\alpha p_{\tau}<q \tau$, the smuggling will be significant (though, apparently, there will be also honest importers).

The last formulae allow to solve the problems of optimization of a level of the customs duties in different formulations: with one, two or even with three goal functions. For example, the optimal value of import $y_{\tau}=\sqrt{\frac{M\left(x^{0}+z_{\tau}\right)}{q(1+\tau)}}-x^{0}-z_{\tau}$ as before, is obtained from the condition $\frac{d}{d y} D=0$. Then the state will receive:

$$
S=\tau q\left[\sqrt{\frac{M\left(x^{0}+z_{\tau}\right)}{q(1+\tau)}}-x^{0}-z_{\tau}\right]+\sqrt{\frac{M q(1+\tau)}{x^{0}+z_{\tau}}}\left(s x^{0}+\alpha z_{t}\right) .
$$

It is possible to apply take this results of for obtaining $z_{\tau}, \alpha$, by a known value for $S$. If $z_{\tau}, \alpha$ are given, it is possible to calculate the optimal $\tau, s$.

\section{Conclusions}

The paper deals with the problem of determining the import duties for a product that is also produced within the country. In this paper all participants are divided on two groups: one of support and another of opponents. The first one could consist of one country, which protects. The second one unites all other country with common actions.

The constructed models indicate how the authorities could calculate the optimal import tariff if some protection is accepted. The models enable identification of customs quality or smuggling in the country.

\section{Acknowledgments}

I am most appreciative to the reviewers for their comments and useful suggestions. The NSF Grant CCR-9505732 supports this work.

\section{References}

[1] R.C. Feenstra, Advanced International Trade: Theory and Evidence, Princeton University Press, New Jersey, N.J., 2008. 
[2] H.C. Lodhia, The Irrationality of Rational Expectations: An Exploration into Economic Fallacy, Warwick University Press, Warwick, UK, 2005.

[3] D.R. Koleva, Th.J. Prusab, Tariff policy for a monopolist in a signaling game, Journal of International Economics, 49, No. 1 (1999), 51-76.

[4] X. Yang, W. Cheng, H. Shi, Ch. Tombazos, An Inframarginal Approach to Trade, World Scientific Pub. Co Inc, New York, N.Y., 2005.

[5] R. Roberts, The Choice: A Fable of Free Trade and Protection, Prentice Hall, New Jersey, N.J., 2006.

[6] S. Katayama, H.W. Ursprung, International Economic Policies in a Globalized World, Springer, New York, N.Y., 2012.

[7] A. Razin, H-J. Vosgerau, Trade and Tax Policy, Inflation and Exchange Rates: A Modern View, Springer, New York, N.Y., 2011.

[8] R. Christou, International Agency, Distribution and Licensing Agreements, Sweet \& Maxwell, New York, N.Y., 2011.

[9] J.N. Bhagwati, P. Krishna, A. Panagariya, Trading Blocs: Alternative Approaches to Analyzing Preferential Trade Agreements, MIT Press, Massachusetts, 1999.

[10] Z. Arashiro, Negotiating the Free Trade Area of the Americas, Palgrave Macmillan, New York, N.Y., 2011.

[11] S. Seiichi Katayama, (Editor), H. Ursprung, International Economic Policies in a Globalized World, Springer, New York, N.Y., 2012.

[12] T.G. Packard, J. Koettl, C. Montenegro, In from the Shadow: Integrating Europe's Informal Labor, World Bank Publications, Washington D.C., 2012. 